DOI: http://doi.org/10.21698/simi.2018.ab09

\title{
MICROORGANISMS DIVERSITY FROM AN INNOVATIVE GRANULAR ACTIVATED SLUDGE SYSTEM
}

\author{
Costel Bumbac ${ }^{1}$, Elena Manea ${ }^{1}$, Sabrina Rosoiu ${ }^{2}$, Alina Roxana Banciu ${ }^{1}, \underline{\text { Mihai Nita-Lazar }}^{1}$ \\ ${ }^{1}$ National Research and Development Institute for Industrial Ecology - ECOIND, 71-73 Drumul \\ Podu Dambovitei, district 6, Bucharest, 060652, mihai.nita@incdecoind.ro, Romania \\ ${ }^{2}$ Center for Surface Science and Nanotechnology, University of Polytechnica Bucharest, 313 \\ Splaiul Independentei, 060042, Bucharest, Romania
}

Keywords: activated sludge, bacteria

\section{Introduction}

The use of microalgae-bacteria granules can achieve superior purification efficiencies compared to the conventional sludge process, especially by reducing energy input and recovering energy from residual biomass. The exploitation manner of the morphological and metabolic peculiarities of the two groups (bacteria-algae) is important and directly related to the efficiency of waste water treatment in the process. The modulation of the physico-chemical parameters of the influent and effluent effluent from a microalgae-bacterial sequenced bioreactor (during the start-up period and stationary conditions, as well as a consequence of the variations of the operational conditions) were correlated with the population microalgae and bacteria, characterized by modern molecular biology techniques. Their morphologicalstructural informations were collected by microscopy techniques. The results revealed a constant presence in the number of bacterial populations that adapt and quickly establish a balance between metabolic processes such as nitrification, denitrification, etc.

\section{Materials and methods}

The granular system in sewage treatment processes in sequential operation. The Biostat ${ }^{\circledR}$ Aplus Bioreactor (Sartorius, Germany) was equipped with foaming sensor, feed pump, effluent pump activated by foaming sensor, decanter $(95 \times 20 \mathrm{~mm})$, influent and effluent vessels and an external source of light having a luminous flux of $3980 \mathrm{~lm}$, the light intensity at the outer wall of the bioreactor being $\mu \mathrm{mol} / \mathrm{m}^{2} / \mathrm{s}$. The useful volume of the bioreactor was $1 \mathrm{~L}, 0.5$ liter feed volume, reaction time $-24 \mathrm{~h}$ and biomass settling time $-3 \mathrm{~min}$. The photoperiodicity was set for 15 hours of light: 9 hours of darkness for a period of 24 hours of treatment. The rate of homogeneity of the reaction medium varied between $160 \mathrm{rpm}$ of $200 \mathrm{rpm}$. The purification process was carried out in the absence of mechanical aeration, the oxygen being supplied exclusively by the photosynthesis process carried out by photoautotrophic microalgae in the light phase.

Molecular Biological Techniques Biological samples obtained at different time intervals from the biological reactor have been processed to extract the genetic material. Quantitative analysis of the presence of certain genes belonging to bacterial populations involved in nitrification, denitrification was performed by RT-PCR / qPCR. 


\section{INTERNATIONAL SYMPOSIUM "THE ENVIRONMENT AND THE INDUSTRY", SIMI 2018, BOOK OF ABSTRACTS}

Microscopy assays. The obtained granules were structurally analyzed by advanced microscopy techniques using a Leica M205 FA stereo microscope with PLO APO 2.0x PLAN and APO 1.0x PLAN.

\section{Results and conclusions}

The analysis of microalgae-bacteria granules by microscopic techniques allowed to obtain whole grain images as well as their correlation with the operational parameters of the bioreactor (Figure 1). The results demonstrated relatively similar granules in sizes between 1 and $3 \mathrm{~mm}$.
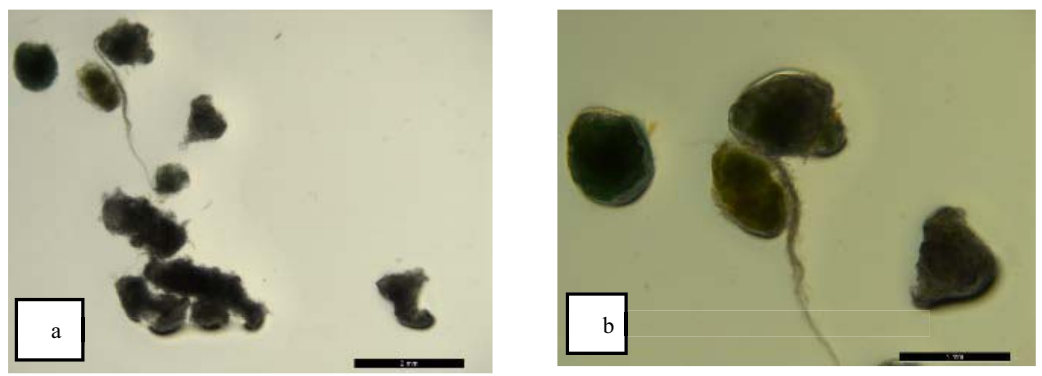

Figure 1. Microscopy images on bright field (a) zoom 0.78x, (b) zoom 1.6x

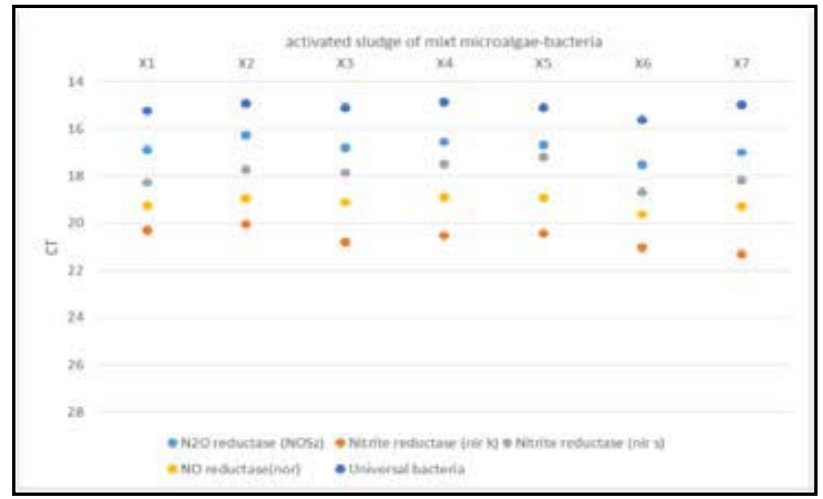

Figure 2. Dynamics of genes involved in nitrification - denitrification processes

Nitrification-denitrification processes have been the primarily responsible for the removal of nitrogen compounds in wastewater treatment systems. Nitrification is the biological oxidation of ammonium to nitrite followed by oxidation of nitrite to nitrate. The results showed no significant changes among the samples collected at various bioreactor working conditions (Figure 2). The oxidation of ammonia in nitrite is carried out by two groups of organisms, ammonium-oxidizing bacteria (Nitrosomonas sp. or Nitrosococcus sp.) and ammonium-oxidizing archaea (Nitrosopumilus sp., and Nitrososphaera sp.).

The results gave information about the structure and function of microorganisms that form the microalga - bacteria mixed granule community, with a special emphasis on those useful biotechnological species, by using modern techniques of molecular biology and microscopy.

\section{Acknowledgements}

This work was carried out whithin PN-III-P4-ID-PCE-2016-0865 Project financed by UEFISCDI, Contract no.84/2017. 